\title{
BMJ Open E-cigarette advertising exposure among South African adults in 2017: findings from a nationally representative cross- sectional survey
}

\author{
Israel Terungwa Agaku (D) ,1,2 Catherine O Egbe (D) , ${ }^{3}$ Olalekan A Ayo-Yusuf ${ }^{1,4}$
}

To cite: Agaku IT, Egbe CO, Ayo-Yusuf OA. E-cigarette advertising exposure among South African adults in 2017: findings from a nationally representative crosssectional survey. BMJ Open 2021;11:e048462. doi:10.1136/ bmjopen-2020-048462

- Prepublication history for this paper is available online. To view these files, please visit the journal online (http://dx.doi. org/10.1136/bmjopen-2020048462).

Received 29 December 2020 Accepted 29 July 2021

\section{Check for updates}

(c) Author(s) (or their employer(s)) 2021. Re-use permitted under CC BY-NC. No commercial re-use. See rights and permissions. Published by BMJ.

${ }^{1}$ School of Health System \& Public Health, University of Pretoria, Pretoria, South Africa ${ }^{2}$ Department of Oral Health Policy and Epidemiology, Harvard School of Dental Medicine, Boston, MA, USA ${ }^{3}$ Alcohol, Tobacco and Other Drug Research Unit, South African Medical Research Council, Pretoria, South Africa ${ }^{4}$ Africa Centre for Tobacco Industry Monitoring and Policy Research, Sefako Makgatho Health Sciences University, Pretoria, South Africa

Correspondence to

Professor Olalekan A Ayo-Yusuf; lekan.ayo-yusuf@smu.ac.za

\section{ABSTRACT}

Objectives In South Africa, the Control of Tobacco and

Electronic Delivery Systems Bill seeks to regulate ecigarettes as tobacco products, including their advertising, promotion and sponsorship. Population data on ecigarette advertising in South Africa are needed to inform public health programs, practice and policy. We examined self-reported e-cigarette advertising exposure during 2017.

Design Cross-sectional.

Setting Household-based survey.

Participants 3063 individuals who participated in the 2017 South African Social Attitudes survey, a nationally representative, in-person survey of the noninstitutionalised civilian adult population aged $\geq 16$ years Exposure 'In the past 12 months, have you seen advertisements or promotions for e-cigarettes (including eshisha, e-pipe) on any of the following media: newspapers/ magazines, billboards, in the malls or any other source?'

Main outcomes Beliefs and attitudes regarding ecigarettes.

Findings Participants' mean age was 37.7 years. Overall, $20.1 \%$ reported exposure to e-cigarette advertisements. By age, exposure was most prevalent among those aged 16-19 years (24.6\%). Top sources of exposure among those exposed were stores, $40.7 \%$; malls, $30.9 \%$; and television, $32.5 \%$. Of those aware of e-cigarettes, $61.2 \%$ believed 'e-cigarette advertisements and promotion may make adolescents think of smoking traditional cigarettes'; $62.7 \%$ believed that 'e-cigarette advertisements and promotions may make ex-smokers think of starting smoking cigarettes again'; and $59.5 \%$ supported the statement that 'e-cigarette smoking should be banned indoors just as traditional cigarette smoking'. Notably, teens aged 16-19 reported the lowest prevalence (49.0\%) of those believing that 'e-cigarette advertisements and promotion may make adolescents think of smoking traditional cigarettes', whereas this percentage was highest among those aged 55-64 years (73.2\%).

Conclusion Comprehensive regulatory efforts are needed to address e-cigarette advertising, marketing and sponsorship in order to protect public health. The urgent enactment of the new tobacco control legislation, The Control of Tobacco Products and Electronic Delivery Systems Bill, can help reduce youth exposure to ecigarette advertising in South Africa.

\section{Strengths and limitations of this study}

- We used a nationally representative survey to collect information on exposure to e-cigarette advertisements among a large sample of South African adults.

- The study is very timely and has potential to inform public health practice, programmes and policy in South Africa and the region overall.

- Because of the cross-sectional design, only associations can be drawn because of the inability to establish temporality between exposure to e-cigarette advertisements and study outcomes.

With the self-reported exposure to e-cigarette advertisements, there may be measurement bias, including misreporting.

\section{INTRODUCTION}

It is well established that exposure to tobacco advertising and promotional activities is causally related to the initiation of tobacco products. ${ }^{1}$ This evidence has also been demonstrated for e-cigarettes, ${ }^{2-6}$ which is not surprising, given that e-cigarette advertisements have adopted many of the themes used to market combustible cigarettes. ${ }^{78}$ While South Africa has outlawed all forms of tobacco advertising, promotion and sponsorship for cigarettes and other conventional tobacco products on certain media, ${ }^{9}$ this prohibition does not currently apply to e-cigarettes because they have not been regulated as tobacco products ever since they were introduced into the South African market about 10 years ago. ${ }^{10}{ }^{11}$ E-cigarettes have thus been widely advertised on media in South Africa, including on television (TV), within malls, radio, social media and the internet (figures 1 and 2, online supplemental figures 1; 2). Effective 2018, South Africa's Advertising Standards Authority (ASA) on receiving public complaint, entered into an agreement with one of the major e-cigarette 


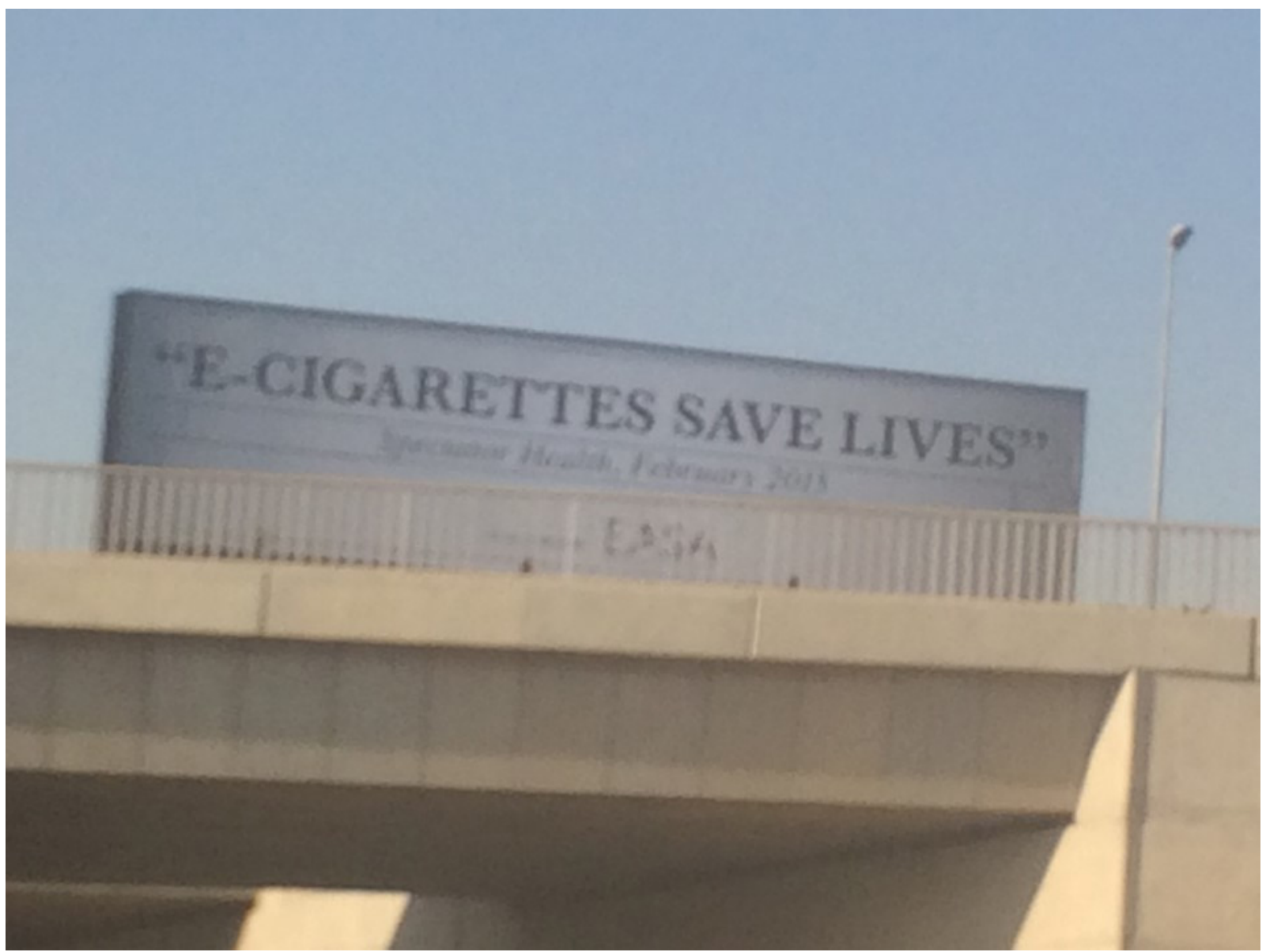

Figure 1 Advertising of e-cigarette with health claims over a billboard in South Africa during 2015

manufacturers in the country to remove certain advertisements that made health claims and glamorised vaping. ${ }^{12}$ This agreement with ASA, while welcome, is only a 'band-aid' solution because it is narrow in scope and authority; other advertising companies who are not members of this professional union (ie, ASA) are not bound to those agreements and can still engage in such advertising as it is not illegal to do so until a law is passed

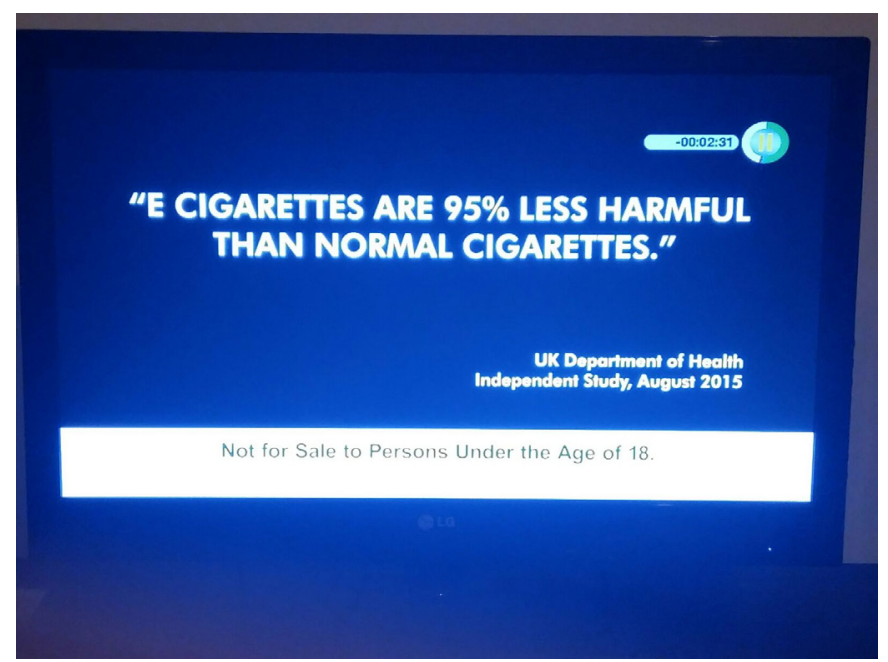

Figure 2 E-Cigarette health claim being shown on television in South Africa during 2016. prohibiting e-cigarette advertising on certain media. The current agreement also relies on self-enforcement by e-cigarette manufacturers which can have limited impact. Given the impact of advertising on youth and young adults, ${ }^{16}$ there is still need for regulation to remove e-cigarette advertising from youth-oriented media. A recent study by Agaku et al showed targeted and persistent efforts by e-cigarette manufacturers in South Africa to continue marketing e-cigarettes over the internet even when the South African government imposed a ban on the sale of tobacco, electronic cigarettes, and related products during a 5-month period early in the COVID-19 pandemic. ${ }^{13}$ Another study showed strategic placement of e-cigarette vape shops as a form of promotion and advertisement in South Africa: Of the at least 240 vape shops identified in South Africa during 2020, 39\% were within a $10 \mathrm{~km}$ radius of a university or college campus, and $65.3 \%$ were within a $20 \mathrm{~km}$ radius. ${ }^{14}$

During 2018, an estimated 1.09 million South Africans aged $16+$ years reported using e-cigarettes although most users reported nondaily use. ${ }^{15}$ Specifically, 295081 South African adults reported using e-cigarettes that year every day, or $0.73 \%$ prevalence, while 794936 persons reported using e-cigarettes some days or $1.98 \%$ prevalence. $^{15}$ South Africa's most recently proposed tobacco control and prevention legislation, The Control of Tobacco and 
Electronic Delivery Systems Bill, intends to deem and regulate e-cigarettes as tobacco products. ${ }^{10}$ This will have immense implications on several aspects of e-cigarette manufacture, design and marketing. For example, it would change how e-cigarettes are advertised, including subjecting e-cigarettes to advertising restrictions on media already prohibited for tobacco products, including radio, $\mathrm{TV}$, print media and the internet.

Given the popularity of e-cigarettes in South Africa, ${ }^{11} 15$ it is critical to measure where people are most exposed to e-cigarette advertisements in South Africa, as well as quantify the association between exposure to e-cigarette advertisements and perceptions of harm, a cognition that precedes experimentation and use. ${ }^{1}$ It is also important to empirically evaluate the veracity of key claims made in e-cigarette advertisements. One central argument is that e-cigarette marketing is directed mainly at smokers ${ }^{16}$; with product taglines like 'vaping designed for smokers' suggesting that the main target niche is adult smokers. Yet, the highly attractive, youth-oriented themes used in marketing e-cigarettes in South Africa belie that claim. An examination of which subgroups are most exposed to e-cigarette advertisements may suggest which segments of the population are being targeted, with implications for product initiation. It is therefore important to capture public opinion on perceived impact of e-cigarettes among vulnerable groups, as well as evaluate support for comprehensive regulation of e-cigarettes as part of broader tobacco control and prevention efforts.

In this study, we used population data to better understand how e-cigarettes are marketed in South Africa. Self-reported exposure and subjective beliefs regarding perceived harm (both individual and population-level harm) and perceived social acceptability of e-cigarettes were examined using the South African Social Attitudes Survey, a nationally representative sample of South African adults aged $\geq 16$ years.

\section{METHODS}

\section{Data source and measures}

The South African Social Attitudes survey is a nationally representative, in-person survey of the noninstitutionalised civilian adult population aged $\geq 16$ years. ${ }^{17}$ The survey is supported by the Human Sciences Research Council using all the 11 official South African languages. SASAS uses a stratified multistaged cluster procedure. Within strata (tribal areas, formal rural, formal urban and informal urban), selection occurs probabilistically at three stages (enumeration areas, households and individuals). At the first stage (primary sampling unit), enumeration areas are selected at random. In the second stage, households are selected. In the third stage, an individual is selected from within the list of eligible household members. Final weights are computed as product of the inverse of the selection probabilities at each stage of selection. For this study, the 2017 cycle of the survey, conducted during January-March 2017, was used ( $\mathrm{n}=3063$ individuals).

In addition to data obtained on respondents' sociodemographic characteristics, all respondents were asked of their exposure to e-cigarette advertisements within the past 12 months. Exposure was measured thus: 'In the past 12 months, have you seen advertisements or promotions for e-cigarettes (including e-shisha, e-pipe) on any of the following media: newspapers/magazines, billboards, in the malls or any other source?' Respondents then checked their exposure status on each individual medium with the possibility to select more than one medium where applicable. Individuals who had never heard about e-cigarettes prior to the study were classified as being unexposed to e-cigarette advertisements.

E-cigarette relative/comparative harm perception was assessed thus: 'In your opinion, are (Electronic cigarettes) less harmful, more harmful, or just as harmful as smoking 'regular' cigarettes?' Response options include 'Less'; 'More'; 'Just As'; 'Don't know', and 'Never heard of product'. People answering 'Never heard of product' (ie, e-cigarettes) were excluded from the denominator in certain analyses where the intent was to assess subjective beliefs about e-cigarettes, including perceived harm. For such questions, it was only reasonable to assess them among those who were aware of what e-cigarettes are. There may be limited face validity in whatever opinions are provided about e-cigarettes from individuals who have no knowledge about e-cigarettes; for this reason, the survey used skip patterns for such questions to restrict to only those aware of e-cigarettes.

Among people who had ever heard about e-cigarettes, the survey further asked their opinions regarding e-cigarettes using the following constructs: (1) 'e-cigarette advertisements and promotion may make adolescents think of smoking traditional cigarettes'; (2) 'e-cigarette advertisements and promotions may make ex-smokers think of starting smoking cigarettes again'; (3) 'e-cigarette smoking should be banned indoors just as traditional cigarette smoking'; (4) 'e-cigarette advertisement and promotions should be banned just as with traditional cigarettes' and (5) 'Seeing people smoke e-cigarettes in public makes smoking look acceptable'. For each of (1)-(5), categorical response options were: 'strongly agree'; 'agree'; 'neither agree nor disagree'; 'disagree'; 'strongly disagree'; an answer of either 'strongly agree' or 'agree' was considered an affirmative response. We were interested in comparing how prevalence of these belief constructs compared between those exposed to e-cigarette advertisements vs those not exposed. All individuals aware of e-cigarettes were therefore included in the denominator, regardless of their exposure status in relation to e-cigarette advertisements.

Participants who self-reported secondhand smoke exposure (SHS) in the past 30 days 'At work', at a 'Café/ restaurant', or at a 'Shebeen, bar or club', were classified as being exposed to SHS in a public area. Current users of any tobacco product were persons who reported use 
frequency of 'Currently Every day', or 'Currently Some days' for $\geq$ one of the following products: 'Manufactured Cigarettes'; 'Roll-your-own cigarettes (Zol)'; 'Hubbly or hookah or water pipe'; 'Electronic cigarettes (vapour cig) '; 'Cigars or Pipes' or 'Snuff (nasal or oral)'. Current users of any combustible tobacco product were persons who reported current use of $\geq$ one of the following: 'Manufactured Cigarettes'; 'Roll-your-own cigarettes (Zol)'; 'Hubbly or hookah or water pipe' or 'Cigars or Pipes'.

Quit attempts were assessed within the past 12 months and defined as having made $\geq 1$ quit attempt in the past 12 months. This was assessed with the question: 'Within the last 12 months when you attempted to quit, did you get any help?' Categorical response options were: 'yes'; 'no'; 'can't say'; 'I didn't think I needed help' or 'I did not attempt to quit in the last 12 months'. Any answer other than the last response was taken as an indication of having made a quit attempt in the past 12 months.

\section{Analyses}

SASAS data were weighted to yield estimates that are generalisable to the South African adult population. Unadjusted subgroup comparisons were done with $\chi^{2}$ tests. Within multivariable logistic regression analyses, e-cigarette-related perceptions and subjective beliefs were modelled as a function of e-cigarette advertisement exposure. The outcomes used as markers of perceived harm and perceived social acceptability were: (1) perception e-cigarettes are less harmful than combustible cigarettes or don't know the relative harm; (2) belief that 'e-cigarette advertisements and promotions may make adolescents think of smoking traditional cigarettes'; (3) belief that 'e-cigarette advertisements and promotions may make ex-smokers think of starting smoking cigarettes again'; (4) support that 'e-cigarette smoking should be banned indoors just as traditional cigarette smoking'; (5) support that 'e-cigarette advertisement and promotions should be banned just as with traditional cigarettes' and (6) belief that seeing people use e-cigarettes in public 'makes smoking look more acceptable'. Because the last indicator was related to e-cigarettes affecting social norms regarding smoking in public places, we created an independent variable that assessed whether participants reported: exposure to SHS in a public place, exposure to e-cigarette advertising, and the interaction of these two exposures. Participants were therefore classified as being exposed to: (1) neither SHS nor e-cigarette advertising; (2) SHS only; (3) e-cigarette advertising only; (4) both SHS and e-cigarette advertising. The rationale for exploring this interaction term in relation to the e-cigarette subjective beliefs was rooted in the following arguments: (1) Both SHS and secondhand e-cigarette aerosol contain similar substances shown to be harmful or potentially harmful, although to varying degrees. ${ }^{6}$ While a major theme of public health messages in recent times has been that no tobacco product is safe, ${ }^{16}$ the frequency with which people are exposed to pro-tobacco messages/cues via advertisements, SHS exposure or both, may impact the extent to which public health messages resound with target audiences. (2) Both SHS exposure in public areas and e-cigarette advertisements can modify social norms, both injunctive norms (perceived acceptability) and descriptive norms (perceived prevalence). ${ }^{17}$ The presence of visual cues in advertisements and/or public spaces where smoking occurs could also trigger relapse among ex-smokers. (3) The physical similarities between some marketed e-cigarettes and regular cigarettes might make it hard to tell them apart from a distance. This becomes even more challenging when these products are being used in outdoor places, especially in the context of smoke-free policies that apply to cigarettes but not e-cigarettes. Enforcement in such circumstances becomes hard if it is difficult to tell them apart. Secondarily, use of e-cigarettes in indoor public areas may contribute to erosion of public compliance with smoke-free policies. Notably, e-cigarette advertisements have sometimes marketed these products as viable alternatives to accessing nicotine in situations where it is not possible to smoke regular cigarettes. ${ }^{8}$ Examining how joint exposure to e-cigarette advertising and SHS exposure in public places influences support for banning of both public use of cigarettes and e-cigarettes is therefore an issue of public health interest.

For each of the six outcomes of interest, a separate logistic regression model was fitted, controlling for age, gender, race and education. Never tobacco users and current users of any combustible tobacco product were analysed as separate strata within these multivariable analyses. For the analyses among current users of any combustible tobacco product, we also assessed associations with making a quit attempt, controlling for the same factors mentioned above. Statistical procedures were performed with R V.3.6.2 and Stata V.14.

\section{Patient and public involvement}

The tobacco questions fielded in SASAS were informed by in-depth review of the policy landscape to ensure the developed research question and outcome measures were highly aligned with the priorities of policy-makers and the public. Members of the public weighed in during cognitive testing of the survey instruments prior to the survey being fielded; this was to ensure the survey questions were well understood. Participants were recruited regardless of their nationality or citizenship, in households spread throughout the country's nine provinces. Trained members of the public also participated in fielding of the survey, including full-time regional coordinators and part-time field teams (eg, quality assurers/supervisors and fieldworkers). Target audience for the data in this study include policy-makers, the media, researchers and public health practitioners, as well as members of the general public. 


\section{RESULTS}

\section{Characteristics of the study population}

Overall, participants' mean age was 37.7 years, with reported ages ranging from 16 to 97 years. Within age groups, distribution of the population was as follows: $16-19$ years $(10.2 \%), 20-24$ years $(13.9 \%), 25-34$ years $(26.5 \%), 35-44$ years $(19.0 \%), 45-54$ years $(13.4 \%)$, $55-64$ years $(9.3 \%)$ and 65 tyears $(7.6 \%)$. By gender, $51.8 \%$ identified as female. By province, distributions were: Western Cape (12.2\%), Eastern Cape (11.7\%), Northern Cape (2.2\%), Free State (5.3\%), KwaZulu-Natal (18.4\%), North West (6.7\%), Gauteng (25.9\%), Mpumalanga $(7.7 \%)$ and Limpopo (10.0\%).

\section{Prevalence of exposure to e-cigarette advertising}

Overall, 20.1\% of South African adults reported being exposed to an e-cigarette advertisement in 2017 (table 1). Exposure was most prevalent among those: with $>$ matric (30.2\%), those with 'much higher' income relative to their family needs $(40.2 \%)$, Indians/Asians $(43.6 \%)$ and whites $(42.2 \%)$ and former tobacco users $(36.2 \%)$. By e-cigarette ever use status, e-cigarette advertisement exposure was over two-fold higher among ever $(55.7 \%)$ than never e-cigarette users $(19.3 \%, \mathrm{p}<0.001)$. By province, exposure to e-cigarette advertisements ranged from a low of $4.7 \%$ in Mpumalanga, to highs of $31.8 \%$ in Gauteng and $33.0 \%$ in KwaZulu-Natal $(\mathrm{p}<0.001)$. Exposure prevalence was $24.6 \%$ among those aged 16-19 years; among the oldest age group, it was $12.7 \%$. (figure 3 ).

Among the South African population aged $\geq 16$ years, reported prevalence of exposure to e-cigarette advertisements was as follows: stores, $8.2 \%$; malls, $6.2 \%$; TV, $6.5 \%$; magazines, $4.4 \%$; radio, $4.0 \%$; billboards, $3.0 \%$ and other sites, $2.1 \%$. Among the adult population who reported exposure to any source of advertisement, reported source of exposure to e-cigarette ads was as follows: stores, 40.7\%; TV, 32.5\%; malls, 30.9\%; magazines, $22.1 \%$; radio, $19.9 \%$; billboards, $15.0 \%$ and other sites, $10.2 \%$. Most of those exposed reported exposure on only one medium (59.8\%), whereas $20.3 \%$ reported exposure on two media, and $12.7 \%$ on three. Only a small percentage reported exposure on four or more media.

\section{Tobacco-related perceptions and subjective beliefs}

Of those aware of e-cigarettes, $61.2 \%$ believed 'e-cigarette advertisements and promotion may make adolescents think of smoking traditional cigarettes'; $62.7 \%$ believed that 'e-cigarette advertisements and promotions may make ex-smokers think of starting smoking cigarettes again'; $59.5 \%$ supported the statement that 'e-cigarette smoking should be banned indoors just as traditional cigarette smoking' (table 1 ). Furthermore, $60.6 \%$ of those aware of e-cigarettes supported the statement that 'e-cigarette advertisement and promotions should be banned just as with traditional cigarettes', and $56.4 \%$ believed that 'Seeing people smoke e-cigarettes in public makes smoking look more acceptable'. Notably, teens aged 16-19 reported the lowest prevalence $(49.0 \%)$ of those believing that "e-cigarette advertisements and promotion may make adolescents think of smoking traditional cigarettes', whereas this percentage was highest among those aged 55-64 years $(73.2 \%)$. Similarly, former tobacco users reported the lowest percentage of those believing that 'e-cigarette advertisements and promotions may make ex-smokers think of starting smoking cigarettes again' $(22.5 \%)$-one-third lower than the percentage seen among current $(63.6 \%)$ and never $(65.5 \%)$ tobacco users.

\section{Adjusted relationship between exposure to e-cigarette advertising and tobacco-related perceptions and subjective beliefs}

Within subgroup analyses restricted to only never tobacco users, those exposed to e-cigarette advertisements had $44 \%$ lower odds of agreeing that seeing people use e-cigarettes in public makes smoking more acceptable compared with those exposed to neither SHS in public places nor to e-cigarette advertisements (adjusted OR, AOR $0.56,95 \%$ CI 0.32 to 0.97 ); this was after adjusting for age, gender, race and education (table 2). Similarly, never tobacco users exposed to both e-cigarette advertisements and SHS in a public place had $66.9 \%$ lower odds than those exposed to neither, of reporting this belief that seeing people use e-cigarettes in public makes smoking look acceptable (AOR 0.33, 95\% CI 0.13 to 0.83 ). The medium over which advertisement exposure occurred was not significantly associated with study outcomes among never tobacco users, after controlling for confounders, with one exception. Never tobacco users exposed to e-cigarette advertisements at malls were significantly less likely to support the ban of e-cigarette use in public places compared with those exposed elsewhere or not exposed at all (AOR $0.49,95 \%$ CI 0.25 to 0.98 ); they were also less likely to support banning of e-cigarette advertisements like those for regular cigarettes (AOR $0.51,95 \%$ CI 0.27 to 0.99 ).

Results from analyses conducted among current smokers of any combustible tobacco product and using those exposed to neither SHS in a public place nor e-cigarette advertisements as the referent group showed the odds of believing that e-cigarette advertisements would make youth think about smoking cigarettes were lower among those exposed to both e-cigarette advertisements and SHS in a public place (AOR 0.19, 95\% CI 0.07 to 0.55 ) as well as those exposed to SHS only (AOR 0.22, $95 \%$ CI 0.07 to 0.70$)$. Similarly, the belief that e-cigarette use in public places would alter social norms in relation to smoking in public was lower among those exposed to both e-cigarette advertisements and SHS in a public place (AOR $0.24,95 \% \mathrm{CI} 0.08$ to 0.68 ) as well as those exposed to SHS only (AOR $0.33,95 \%$ CI 0.11 to 0.99 ). Like the findings noted earlier among never tobacco users, we found an association between exposure to e-cigarette advertisement in malls and pro-e-cigarette perceptions among current smokers of any combustible tobacco product. Exposure to e-cigarette advertisements within a mall was associated with lower support for banning e-cigarette use 


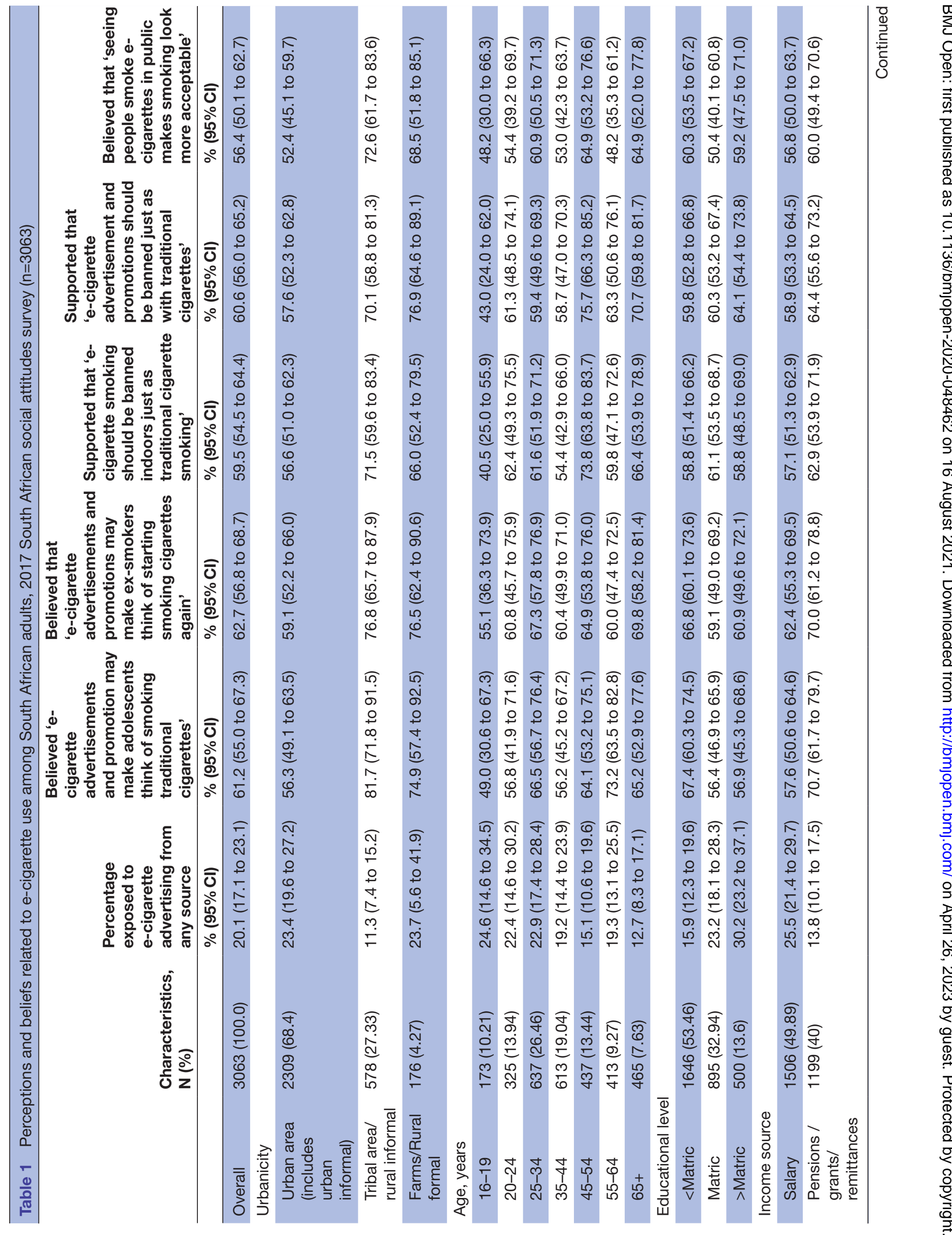




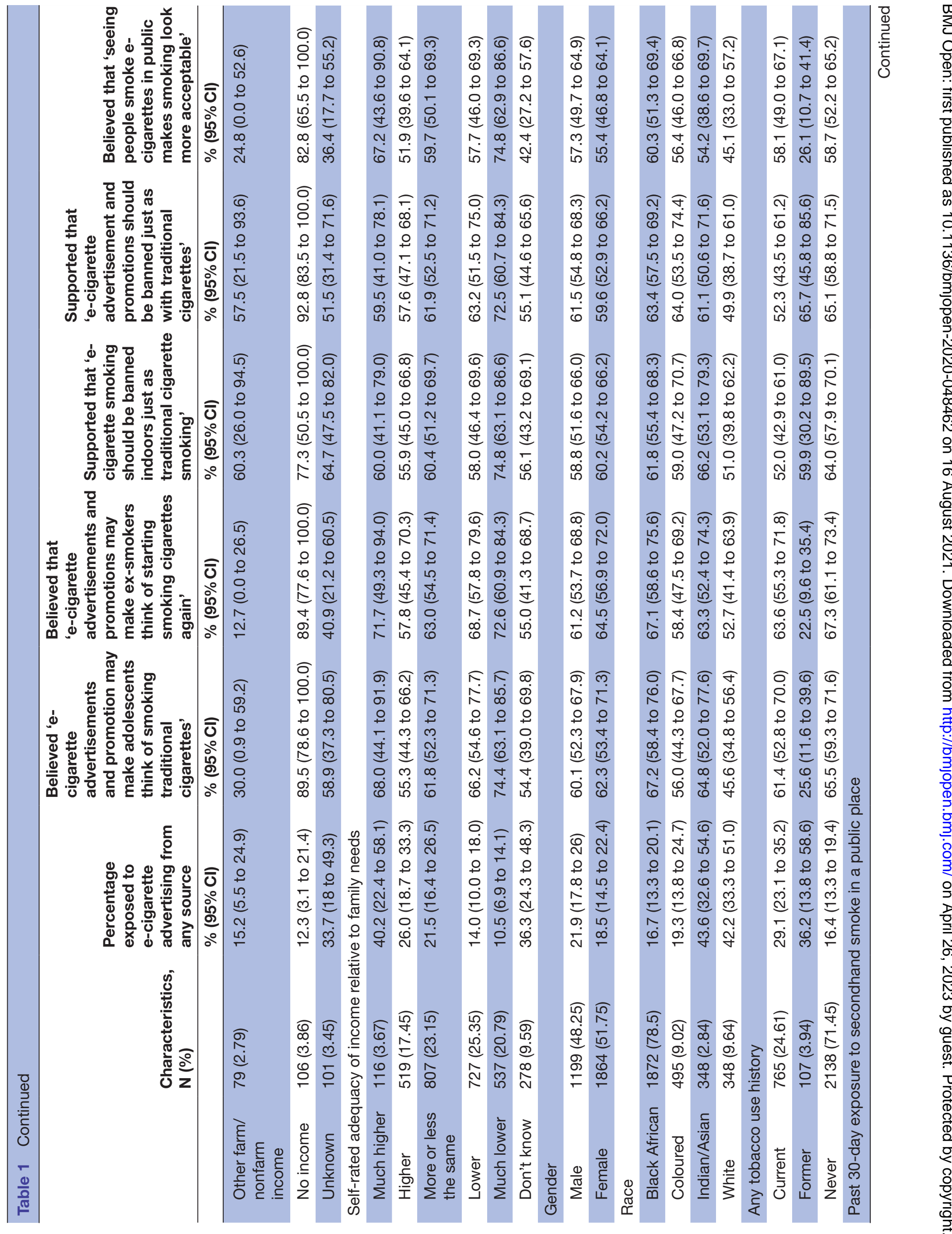




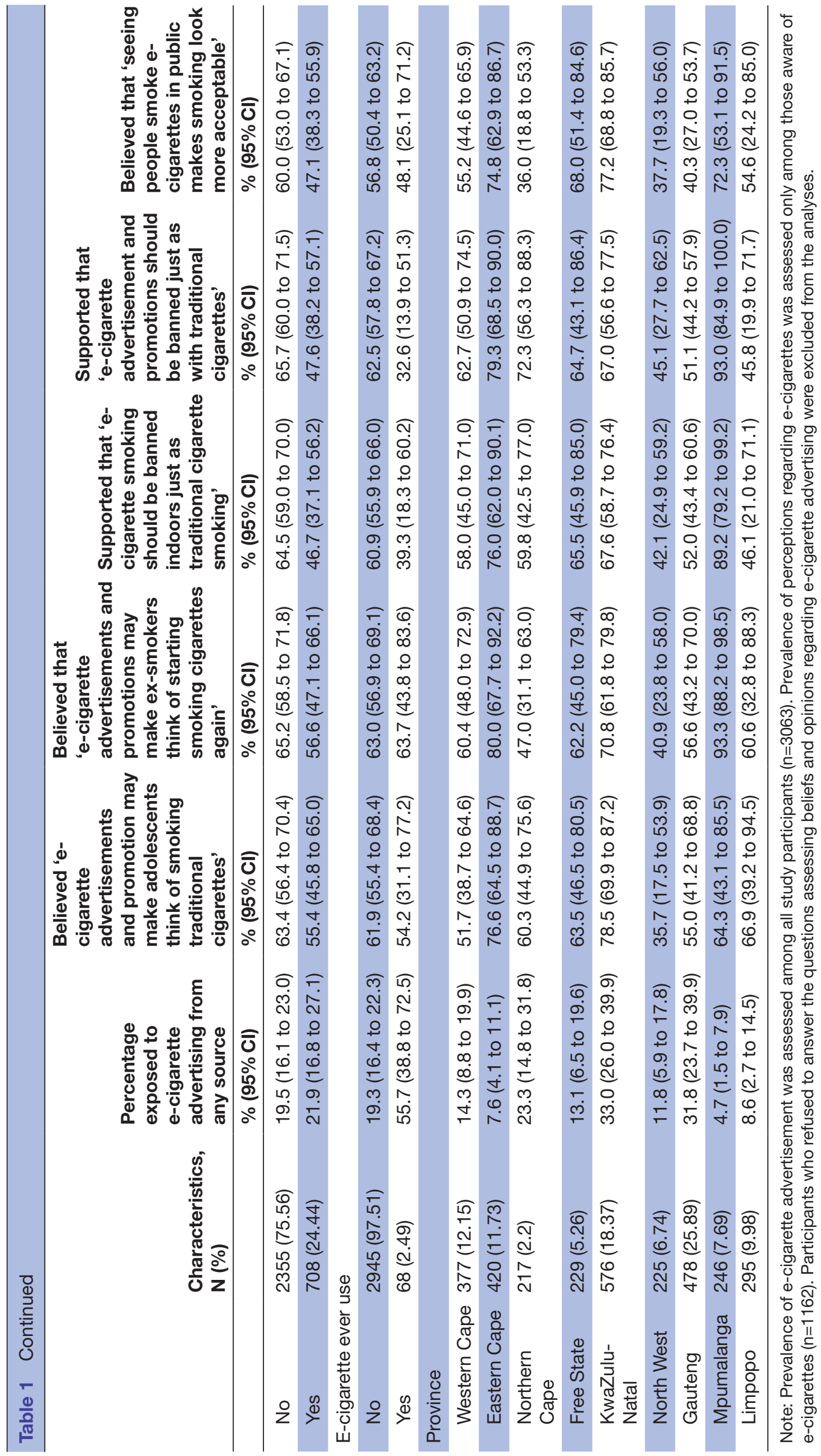




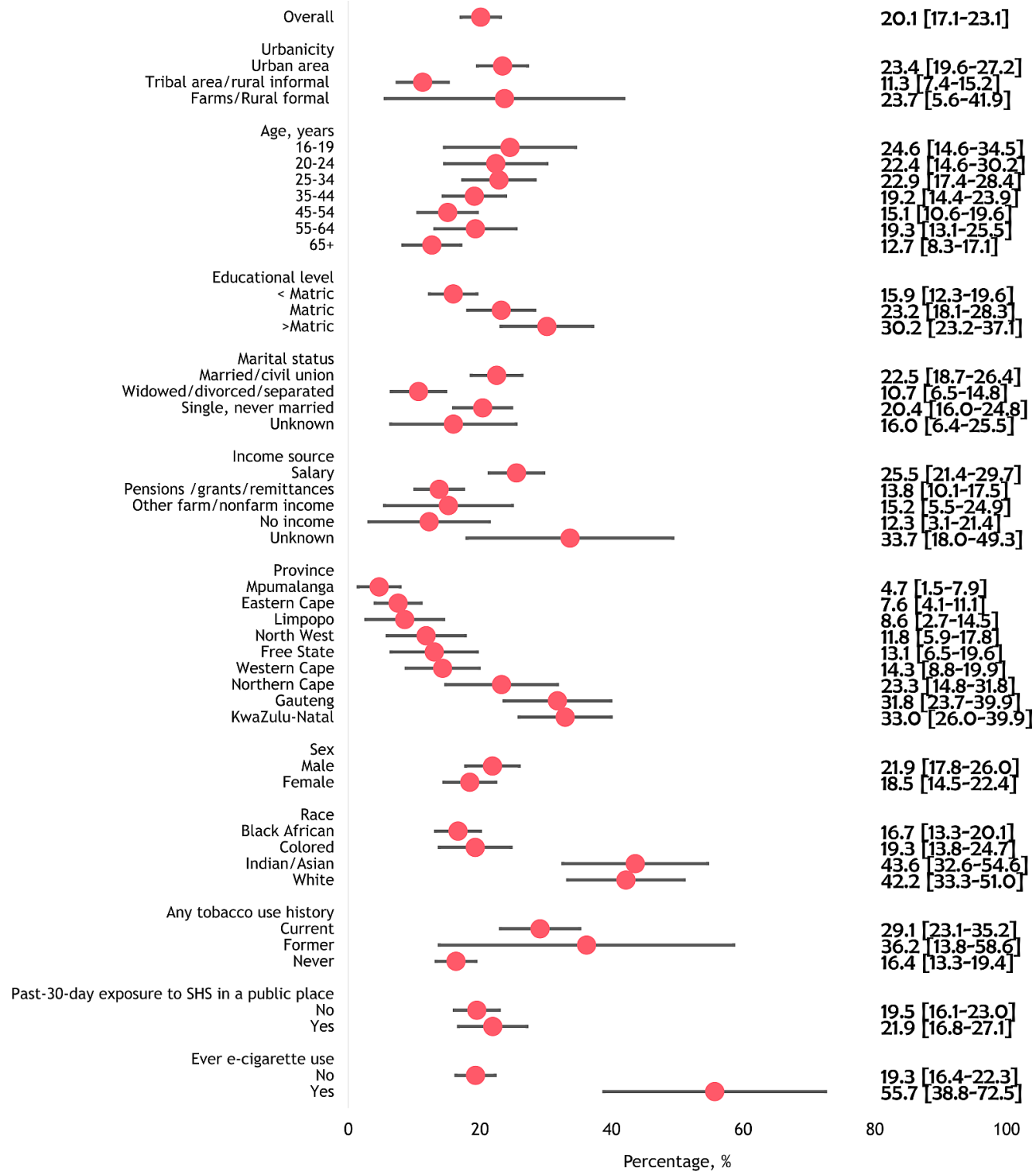

Figure 3 Prevalence of e-cigarette advertisement exposure in the South African adult population, 2017.

in public places (AOR $0.30,95 \%$ CI 0.10 to 0.93 ), or of banning e-cigarette advertisements like those for conventional cigarettes (AOR 0.33, 95\% CI 0.12 to 0.94 ). Odds of making a past-year quit attempt among current smokers of any combustible tobacco product were higher among those exposed to SHS only (AOR 2.82, 95\% CI 1.34 to $5.94)$, but not among those exposed to e-cigarette advertisements only $(p=0.116)$, when compared with those unexposed to either SHS in a public place or to e-cigarette advertisements.

\section{DISCUSSION}

We found that one in five of the population reported exposure to e-cigarette advertisement, and this was higher among youth and young adults; exposure was associated with increased likelihood of perceiving e-cigarette use as acceptable among never tobacco users. Most adults expressed concerns about the potential for e-cigarette advertisements to make youth start smoking. Furthermore, most adults were further in favour of banning e-cigarette advertisements as well as their use in public places.

Understanding the diverse attitudes and opinions of the different segments of the population is important to inform public health practice, policy and programmes, including but not limited to developing targeted educational campaigns. Findings from the youth population are particularly important because they provide insights into observed and perceived risks among this vulnerable group. In our study, teens aged 16-19 years had the highest prevalence of exposure to e-cigarette advertising yet reported the lowest percentage for the belief that 'e-cigarette advertisements and promotion may make adolescents think of smoking traditional cigarettes'. They also were the least likely to support banning of e-cigarette use in public areas, or to support the restriction of e-cigarette advertisements. More public health education is 
Table 2 AORs of the interaction of e-cigarette advertisements and exposure to secondhand smoke in public places, on various markers of harm perception and social norms among never tobacco users and current combustible tobacco smokers separately

\begin{tabular}{|c|c|c|c|c|c|}
\hline & & $\begin{array}{l}\text { Any combustible } t \\
(n=1549)\end{array}$ & smokers & Never tobacco us & $s(n=2465)$ \\
\hline Outcome & Exposure variable & AOR $(95 \% \mathrm{Cl})$ & $P$ value & AOR (95\% Cl) & $P$ value \\
\hline Perception e- & Neither (referent) & & & & \\
\hline cigarettes less harmful & E-cigarette ads only & $1.69(0.55$ to 5.20$)$ & 0.36 & 0.66 (0.37 to 1.16$)$ & 0.15 \\
\hline $\begin{array}{l}\text { than combustible } \\
\text { cigarettes or don't }\end{array}$ & SHS in public places only & 2.10 (0.75 to 5.90$)$ & 0.16 & 1.10 (0.46 to 2.60$)$ & 0.83 \\
\hline know the relative harm & Both & $2.12(0.73$ to 6.21$)$ & 0.17 & 1.87 (0.75 to 4.64$)$ & 0.18 \\
\hline & Neither (referent) & & & & \\
\hline advertisements and & E-cigarette ads only & $0.40(0.14$ to 1.13$)$ & 0.08 & 0.97 (0.56 to 1.69$)$ & 0.91 \\
\hline $\begin{array}{l}\text { promotion may make } \\
\text { adolescents think of }\end{array}$ & SHS in public places only & 0.22 (0.06 to 0.81$)$ & 0.02 & 0.94 (0.34 to 2.56$)$ & 0.90 \\
\hline $\begin{array}{l}\text { smoking traditional } \\
\text { cigarettes' }\end{array}$ & Both & 0.19 (0.07 to 0.56$)$ & $<0.01$ & 1.72 (0.73 to 4.02$)$ & 0.21 \\
\hline Believed that & Neither (referent) & & & & \\
\hline 'e-cigarette & E-cigarette ads only & 0.80 (0.19 to 3.36$)$ & 0.76 & 0.61 (0.36 to 1.03$)$ & 0.06 \\
\hline $\begin{array}{l}\text { advertisements and } \\
\text { promotions may make }\end{array}$ & SHS in public places only & 0.38 (0.07 to 1.97$)$ & 0.25 & $0.40(0.16$ to 1.01$)$ & 0.05 \\
\hline $\begin{array}{l}\text { ex-smokers think } \\
\text { of starting smoking } \\
\text { cigarettes again' }\end{array}$ & Both & 0.48 (0.12 to 1.92$)$ & 0.30 & 0.52 (0.19 to 1.47$)$ & 0.22 \\
\hline & Neither (referent) & & & & \\
\hline cigarette smoking & E-cigarette ads only & 1.49 (0.39 to 5.65$)$ & 0.56 & 0.82 (0.46 to 1.48$)$ & 0.52 \\
\hline $\begin{array}{l}\text { should be banned } \\
\text { indoors just as }\end{array}$ & SHS in public places only & 0.55 (0.13 to 2.27$)$ & 0.40 & 0.83 (0.31 to 2.22$)$ & 0.71 \\
\hline $\begin{array}{l}\text { traditional cigarette } \\
\text { smoking' }\end{array}$ & Both & $0.39(0.12$ to 1.28$)$ & 0.12 & 0.65 (0.27 to 1.54$)$ & 0.32 \\
\hline Supported that & Neither (referent) & & & & \\
\hline 'e-cigarette & E-cigarette ads only & $1.66(0.46$ to 6.03$)$ & 0.44 & 0.91 (0.50 to 1.66$)$ & 0.75 \\
\hline promotions should be & SHS in public places only & 0.49 (0.12 to 2.03$)$ & 0.33 & 0.97 (0.33 to 2.83 ) & 0.95 \\
\hline $\begin{array}{l}\text { banned just as with } \\
\text { traditional cigarettes' }\end{array}$ & Both & 0.40 (0.13 to 1.27$)$ & 0.12 & $0.73(0.30$ to 1.77$)$ & 0.49 \\
\hline Believed that 'Seeing & Neither (referent) & & & & \\
\hline people smoke e- & E-cigarette ads only & $0.47(0.17$ to 1.27$)$ & 0.13 & 0.56 (0.34 to 0.92$)$ & 0.02 \\
\hline $\begin{array}{l}\text { clgarettes In public } \\
\text { makes smoking look }\end{array}$ & SHS in public places only & $0.33(0.11$ to 0.95$)$ & 0.04 & 0.47 (0.18 to 1.22$)$ & 0.12 \\
\hline more acceptable' & Both & $0.24(0.08$ to 0.71$)$ & 0.01 & $0.33(0.13$ to 0.84$)$ & 0.02 \\
\hline
\end{tabular}

Note: Because the exposure variable (e-cigarette advertising exposure) was strongly correlated with e-cigarette use status, the study populations analysed were not stratified further by e-cigarette use status. In the table above, the two mutually exclusive strata of any combustible tobacco smokers $(n=1549)$ and never tobacco users $(n=2465)$ were therefore created regardless of e-cigarette use status. Logistic regression analyses controlled for age, gender, race and education.

AOR, adjusted ORs; SHS, secondhand smoke.

needed to help youth become aware of tobacco industry tactics to market tobacco products towards youth. ${ }^{18-22}$

In our study, exposure to SHS in a public place, and combined exposure to SHS in a public place plus e-cigarette advertisements, both were associated with more positive sentiments towards e-cigarettes. Comprehensive regulatory efforts are needed to address use of tobacco products and other electronic nicotine-delivery devices in public places in an integrated approach. ${ }^{23}$ For example, sale of e-cigarettes within malls might lend itself to experimenting with the device at the point of sale, a violation of complete restrictions on tobacco use in indoor areas of public places. The significant amount of smoking that sill happens in public places in South Africa ${ }^{24}$ might explain why e-cigarettes are commonly promoted in South Africa as 'safer than cigarettes' ${ }^{16}$; with such a reasoning, people might rather have their smoking friends or partners use an e-cigarette when around them in indoor areas than smoke cigarettes. This may explain the tendency of never tobacco users who were exposed to both e-cigarette advertisements and SHS in public places not to support beliefs that were against e-cigarette use in public places, 
as this may have meant restricting the use of e-cigarettes in public places.

To protect public health, pharmacies can voluntarily remove e-cigarettes from their shelves as this serves as unpaid advertisement for these products and reinforces perceptions of healthfulness. Smoke-free policies should be modernised to include restrictions on e-cigarette use in public places. While voluntary adoption of policies prohibiting e-cigarette use in certain public places where smoking is already prohibited is helpful, formalising this legislatively would give it the force of law, expand the protected population covered by such prohibitions and provide mechanisms for enforcement. In addition, the South African National Treasury under the National Department of Finance as well as the National Department of Trade, Industry and Competition, could implement reporting requirements for e-cigarette companies, including expenditures for advertising and promotion. This could be useful for monitoring the activities of e-cigarette manufacturers and protecting youth.

This study's strength is its drawing on nationally representative data to answer questions of public health importance, including exposure to e-cigarette advertisements as well as perceptions regarding consequences of exposure. Nonetheless, there are limitations. First, the cross-sectional design limits causal inferences; only associations can be made. Second, exposure to e-cigarette advertisements was self-reported and may be subject to misreporting. The prevalence estimates are likely underestimated, especially among young adults, given that exposure on social media was not specifically assessed, although it may have been captured under the 'other' category. Third, frequency of exposure was not measured on the media captured. Fourth, the long recall period for assessing exposure (past 12 months) may be prone to cognitive and social biases, and this may well vary differentially between tobacco users vs nonusers. It may be challenging to parse how much of the difference in reported exposure is due to actual differences in exposure versus differences in sensitisation towards and recall of such advertisements. Finally, there may have been some measurement error arising from how survey questions were framed, especially if they were perceived as being ambiguous.

\section{CONCLUSION}

Most South African adults (61.2\%) reported concern that e-cigarette advertisements might make youth think of smoking cigarettes, a justified concern, given that teens aged 16-19 years old in our study reported the highest prevalence of exposure to e-cigarette advertisements. The findings from this study underscore the need for robust surveillance data on the preregulatory e-cigarette landscape; this can serve as a baseline to evaluate future policy changes. The urgent enactment of the new tobacco control legislation, The Control of Tobacco Products and Electronic Delivery Systems Bill, can help reduce youth exposure to e-cigarette advertising in South Africa.
Acknowledgements Special thanks to the South African Human Sciences Research Council (HSRC) for their assistance with data collection.

Contributors ITA led the conceptualisation of the initial manuscript; OAA-Y and COE assisted. ITA, OAA-Y and COE all participated in the statistical analyses, critically reviewed and revised the manuscript, and approved the final manuscript as submitted and agree to be accountable for all aspects of the work.

Competing interests None declared.

Patient consent for publication Not required.

Ethics approval The study was approved by the University of Pretoria's Faculty of Health Sciences' Ethics Review (no. 39/2019).

Provenance and peer review Not commissioned; externally peer reviewed

Data availability statement Data are available on reasonable request. Requests will be considered on a case-by-case basis.

Open access This is an open access article distributed in accordance with the Creative Commons Attribution Non Commercial (CC BY-NC 4.0) license, which permits others to distribute, remix, adapt, build upon this work non-commercially, and license their derivative works on different terms, provided the original work is properly cited, appropriate credit is given, any changes made indicated, and the use is non-commercial. See: http://creativecommons.org/licenses/by-nc/4.0/.

ORCID iDs

Israel Terungwa Agaku http://orcid.org/0000-0002-5116-2961

Catherine 0 Egbe http://orcid.org/0000-0001-5698-6866

\section{REFERENCES}

1 National Center for Chronic Disease Prevention and Health Promotion (US) Office on Smoking and Health. Preventing tobacco use among youth and young adults: a report of the surgeon General. Atlanta (GA): Centers for Disease Control and Prevention (US), 2012. https://www.ncbi.nlm.nih.gov/books/NBK99237/

2 Papaleontiou L, Agaku IT, Filippidis FT. Effects of exposure to tobacco and electronic cigarette advertisements on tobacco use: an analysis of the 2015 national youth tobacco survey. J Adolesc Health 2020;66:64-71.

3 Pierce JP, Sargent JD, Portnoy DB, et al. Association between receptivity to tobacco advertising and progression to tobacco use in youth and young adults in the path study. JAMA Pediatr 2018;172:444-51.

4 Dai H, Hao J. Exposure to advertisements and susceptibility to electronic cigarette use among youth. J Adolesc Health 2016;59:620-6.

5 Singh T, Agaku IT, Arrazola RA, et al. Exposure to advertisements and electronic cigarette use among US middle and high school students. Pediatrics 2016;137:e20154155.

6 National Center for Chronic Disease Prevention and Health Promotion (US) Office on Smoking and Health. E-cigarette use among youth and young adults: a report of the Surgeon General. Atlanta (GA): Centers for Disease Control and Prevention (US), 2012. https://www.ncbi.nlm.nih.gov/books/NBK99237/

7 Haardörfer R, Cahn Z, Lewis M, et al. The advertising strategies of early e-cigarette brand leaders in the United States. Tob Regul Sci 2017;3:222-31.

8 Stanford University research into the impact of tobacco advertising, 2021. Available: https://tobacco.stanford.edu/

9 Tobacco Control Laws. Legislation by country: South Africa, 2017. Available: https://www.tobaccocontrollaws.org/legislation/country/ south-africa/laws

10 Government Gazette. Department of health (2018). invitation for public Comment on the draft control of tobacco products and electronic delivery systems bill, 2018, 2019. Available: https://www. gov.za/sites/default/files/gcis document/201805/41617gon475re.pdf

11 Euromonitor International. Passport. cigarettes in South Africa 2016.

12 African Center for Tobacco Industry Monitoring and Policy Research. E-Cigarette advert to be pulled off air, 2016. Available: https://www. atim.co.za/2018/03/e-cigarette-advert-to-be-pulled-off-air/

13 Agaku IT, Egbe CO, Ayo-Yusuf OA. Circumvention of COVID-19related restrictions on tobacco sales by the e-cigarette industry in South Africa and comparative analyses of heated tobacco product vs combustible cigarette volume sales during 2018-2020. Prev Med 2021;148:106526.

14 Agaku IT, Egbe CO, Ayo-Yusuf OA. Geospatial spread of e-cigarette vape shops in South Africa and the relationship with tobacco product use among adults. Health Place 2021;68:102507. 
15 Agaku IT, Egbe CO, Ayo-Yusuf OA. Potential revenue from taxing e-cigarettes and comparison of annual costs of daily e-cigarette use versus daily cigarette smoking among South African adults. Tob Induc Dis 2021;19:1-14.

16 Vapor Product Association. Save Vaping, 2019. Available: https:// vpasa.org.za/index.php/save-vaping/

17 Agaku IT, Perks SN, Odani S, et al. Associations between public e-cigarette use and tobacco-related social norms among youth. Tob Control 2020;29:332-40.

18 Corey CG, Ambrose BK, Apelberg BJ, et al. Flavored tobacco product use among middle and high school students-United States, 2014. MMWR Morb Mortal Wkly Rep 2015;64:1066-70.

19 Laestadius LI, Penndorf KE, Seidl M, et al. Assessing the appeal of Instagram electronic cigarette refill liquid promotions and warnings among young adults: mixed methods focus group study. $J$ Med Internet Res 2019;21:e15441.
20 Bono RS, Barnes AJ, Lester RC, et al. Effects of electronic cigarette liquid flavors and modified risk messages on perceptions and subjective effects of e-cigarettes. Health Educ Behav 2019;46:197-203.

21 Garrison KA, O'Malley SS, Gueorguieva R, et al. A fMRI study on the impact of advertising for flavored e-cigarettes on susceptible young adults. Drug Alcohol Depend 2018;186:233-41.

22 Agaku IT, Odani S, Armour BS, et al. Adults' favorability toward prohibiting flavors in all tobacco products in the United States. Prev Med 2019;129:105862.

23 King BA, Graffunder C. The tobacco control vaccine: a populationbased framework for preventing tobacco-related disease and death. Tob Control 2018;27:123-4.

24 Ayo-Yusuf OA, Olufajo O, Agaku IT. Exposure to secondhand smoke and voluntary adoption of smoke-free home and CAR rules among non-smoking South African adults. BMC Public Health 2014;14:580. 